\title{
A Case Study on Rehabilitation of RCC Machine Foundation of a Cement Mill Structure
}

\author{
D. Majumdar ${ }^{\# 1}$,M.K Sahis ${ }^{* 2}$, G.C.MANDAL ${ }^{* 3}$ \\ \# Department of Construction Engineering, Jadavpur University, Kolkata, India \\ 11dipeshce@gmail.com, ${ }^{2}$ manojsahis@gmail.com, ${ }^{3}$ kanak.joy@gmai.com
}

\begin{abstract}
The present cement mill is supported over two RC foundations. Foundation at outlet portion is also supporting mill driving motor and gear box and it is higher in size. Foundation at inlet portion is smaller in size and supporting only mill drum slide shoe bearing. Distresses are noticed only in foundation below outlet portion, which is supporting motor and gear box also. This foundation is rectangular in plan and it is a solid RCC foundation. It is supported on hard rock stratum.
\end{abstract}

Electric motor is transmitting driving force to the mill drum through matching gear arrangement. One of the gear tooth was broken and fell into the gap between two teeth. As both driving motor and mill drum gear system .were in rotating condition, broken gear tooth portion created a tremendous amount of horizontal force before stop. That tremendous amount of horizontal force created a huge moment at the base of RCC foundation. Total four nos.of major cracks were noticed on the foundation; some of the cracks are horizontal in nature and some inclined in nature. UPV test was done to ascertain the depth and nature of the cracks. Epoxy grouting and stitching with steel anchor bolt was done to rehabilitate the RCC foundation. After repair works, the machine foundation is working satisfactority without any further distress.

Keyword - Cement Mill, foundation repair, epoxy grout, stitching, RC foundation.

\section{INTRODUCTION}

Cement grinding is a very important and crucial step for cement manufacturing process. Cement Mill is the primary machine for grinding operation. Clinker mixed with gypsum is charged into the cement mill for grinding process. The cement mill is a steel drum type structure to grind clinker into finer cement particles. The main component of cement mill is a mill drum, which is placed in horizontal position and is supported on two slide shoe bearings. Mill drum structure is driven by electrically operated mill motor. Cement mill is a drum type structure filled with iron ball, which rotates around a horizontal axis. During rotation clinker and ball collide with each other to make finely ground cement particles. Main driving force in generated by electric mill motor. The electric mill motor is connected to the mill drum through a gear system as shown in Fig.1. All these machines are supported over concrete foundation.

\section{CAUSES OF Distress}

Driving mill motor rotates in anticlockwise direction and mill drum rotates in opposite clockwise direction. During running condition one tooth of gear shaft attached to driving motor was broken. As it was rotating in anti clockwise direction, due to gravitational force broken part of gear tooth fell into the space between next two gear teeth. Free space between two gear teeth is less than volume of broken gear tooth; as a consequence, a huge horizontal force is created between mill drum and driving motors. This created /induced horizontal force at gear teeth level is transferred to the foundation through anchor bolt and thus generated a huge moment at ground level of mill foundation. Generation of this additional moment resulted cracks on the mill foundation. Causes of distress are schematically shown in Figs.2, 3 \& 4.

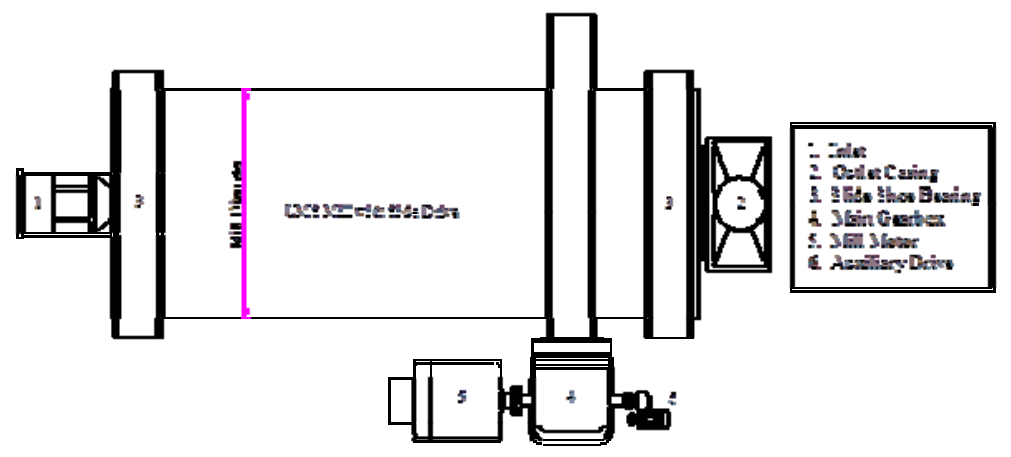

Fig.1: Plan drawing showing different components of Cement Mill. 


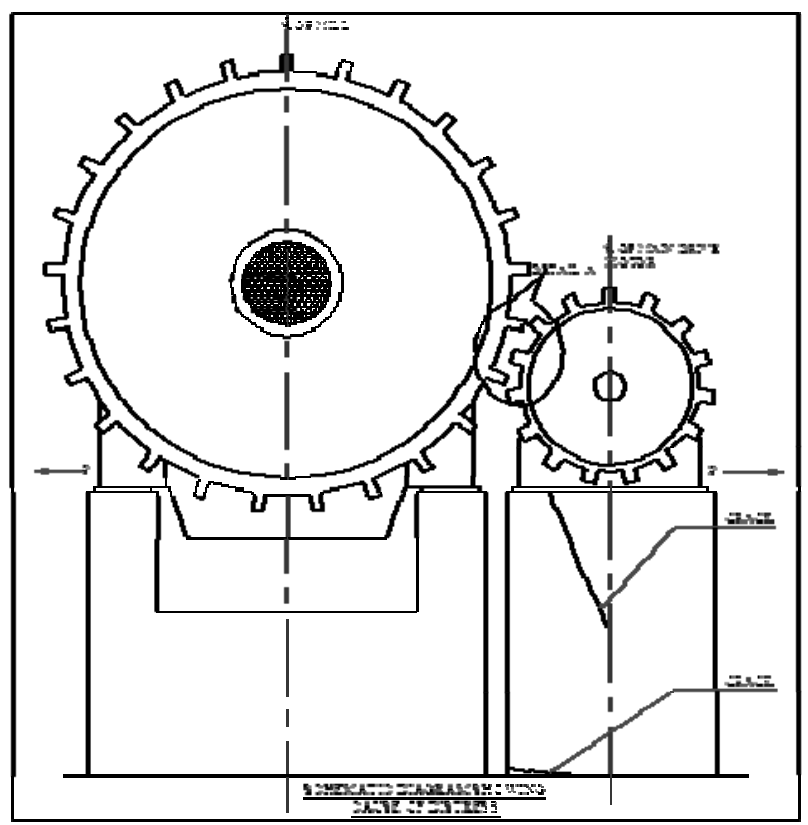

Fig.2 : Sectional elevation showing gear arrangement
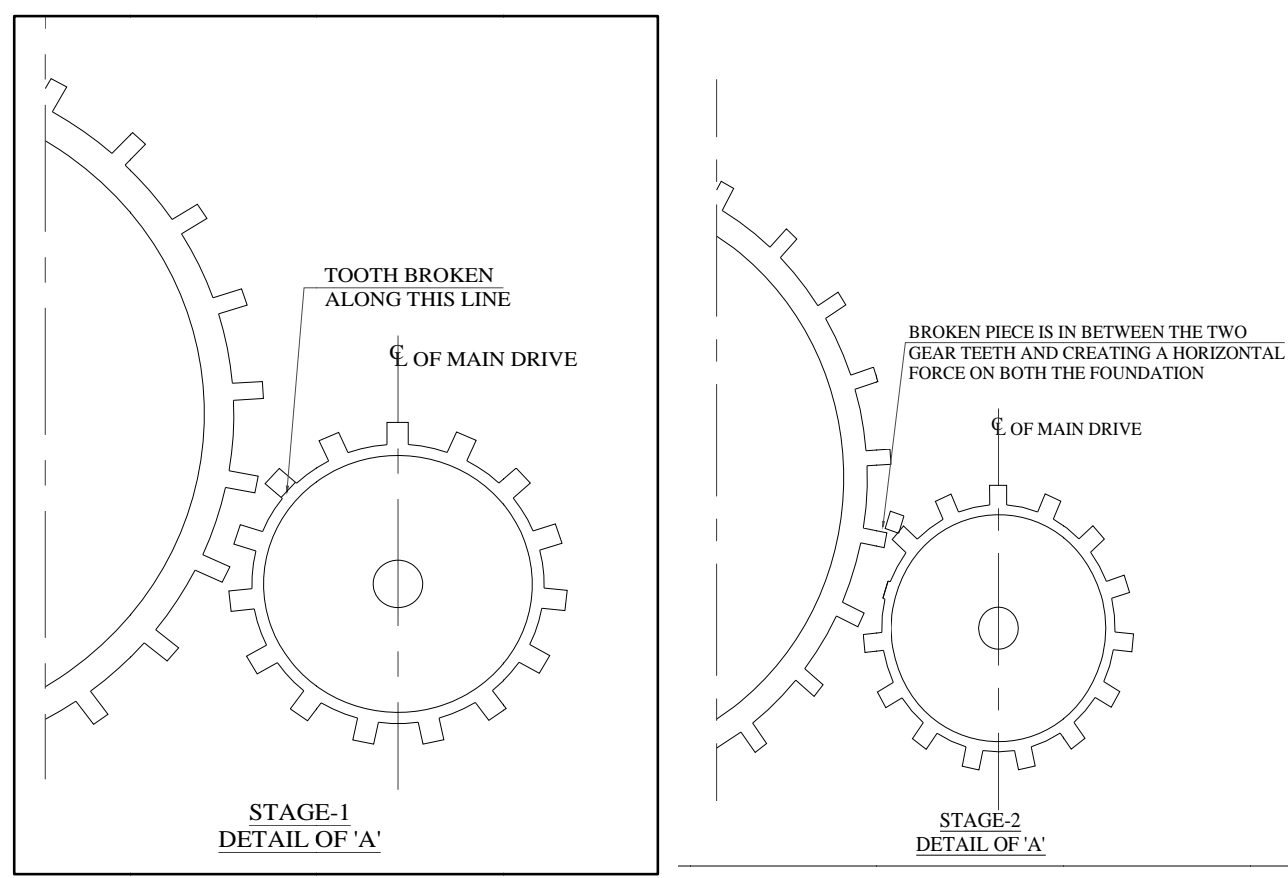

Fig.3:Figure showing broken tooth of gear initiating accident

III.GENERAL DESCRIPTION OF DISTRESS

Thorough visual inspection and Non-destructive tests were carried out to ascertain the existing condition and extent of damage of the foundation. Major damages noticed on the foundation of Cement Mill No. -5 are in the form of cracks. All major cracks are described below with sketch (Fig.5 \& 6).

Crack No -1 which is generated at the ground level. Width of the crack being more at cement mill drum side and narrowing down towards the driving mill motor side.

From close observation, it was noticed that Crack No-1 was generated along the construction joint and that crack was almost through and through type in nature. 


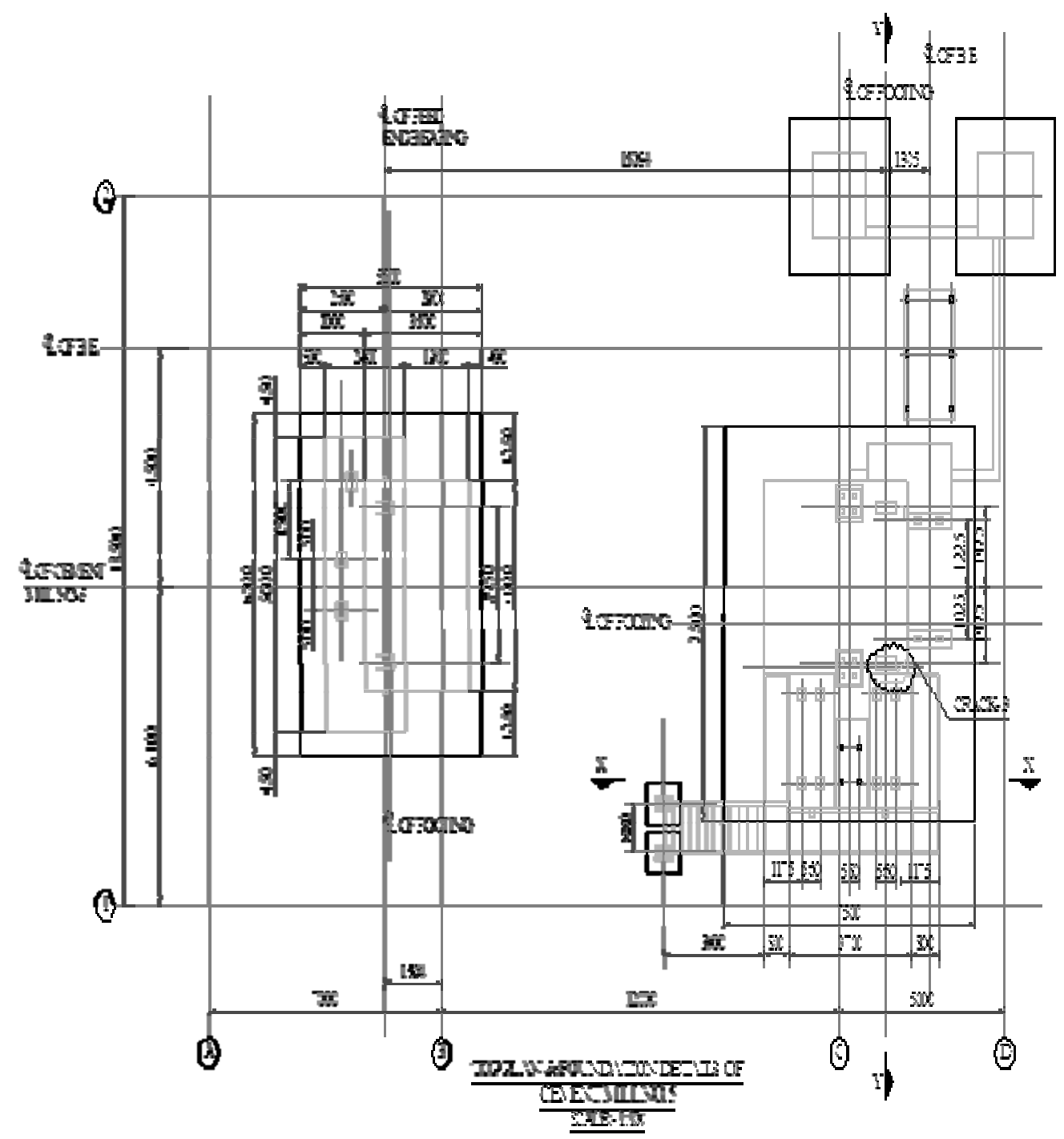

Fig.4: Plan showing different parts of cement mill foundation

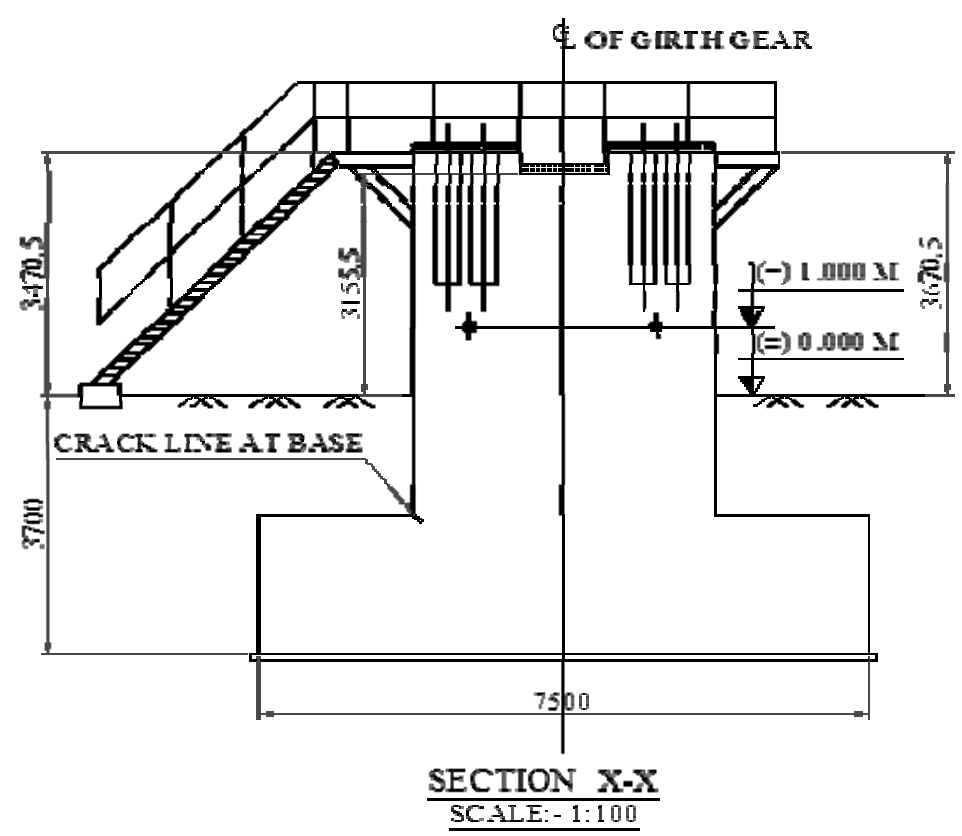

Fig.5: Section showing cement mill foundation 
Crack No-2 is generated at $1.2 \mathrm{~m}$ above Crack No -1 . The nature of the cracks was same as Crack No- 1 . This crack was generated at the level of construction joint of the RC foundation.

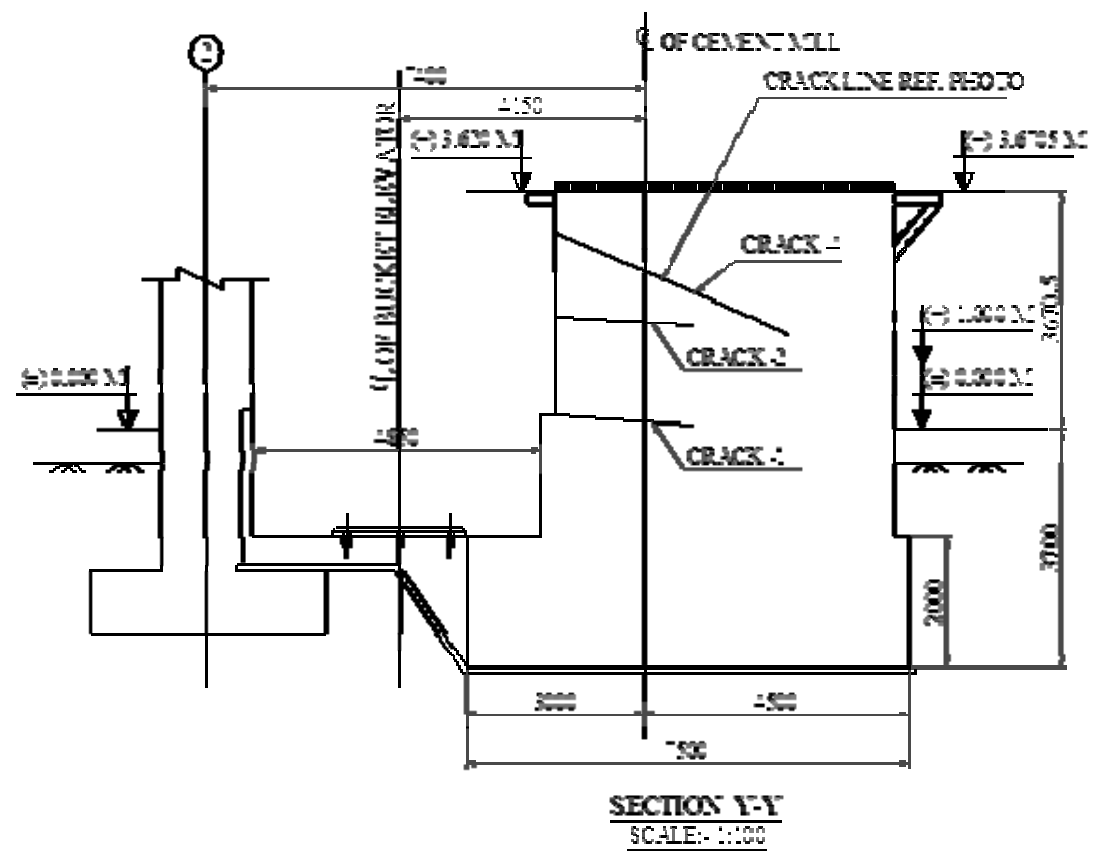

Fig.6: Section showing cement mill foundation in other direction.

Crack No-3: It was vertical in nature. This crack was visible from top level also. From top level this crack was noticed near the anchor bolt of driving motor foundation. The width of the crack is about 10 to $15 \mathrm{~mm}$ at top of foundation and narrowing in nature towards downward.

Crack No-4: It had the narrowest width and nature of the cracks was inclined around $45^{\circ}$ with respect of horizontal plane. Highest width of this crack was noticed on outer surface of foundation at mill drum side.

All major cracks were very prominent in nature and through and through type. UPV test was done to ascertain the condition of existing concrete condition and to ascertain any presence of any further cracks. UPV test was done extensively on the foundation structure. All the cracks had higher width at the mill drum side and width was reducing towards opposite side, which signifies that horizontal force pushed the foundation in an out ward direction. Conditions of concrete at other areas except some cracks are found to be satisfactory as per ultrasonic Pulse Velocity testing method.

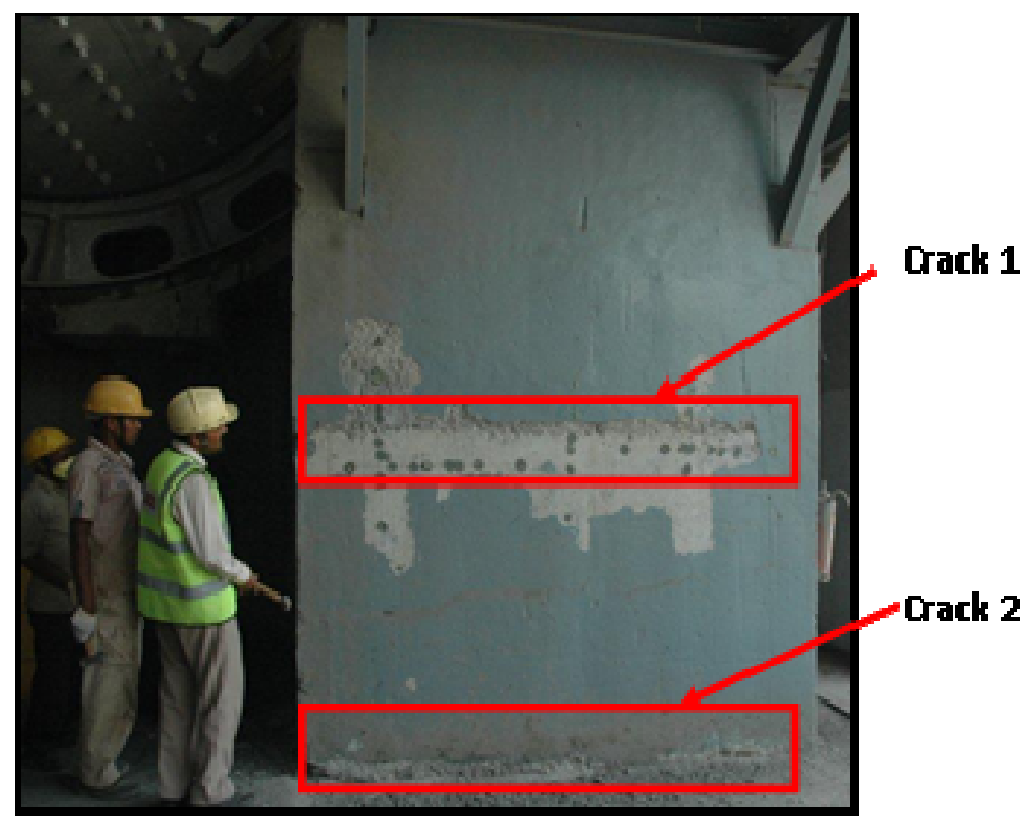

Fig.7: Elevation of cement mill foundation showing major crack position 


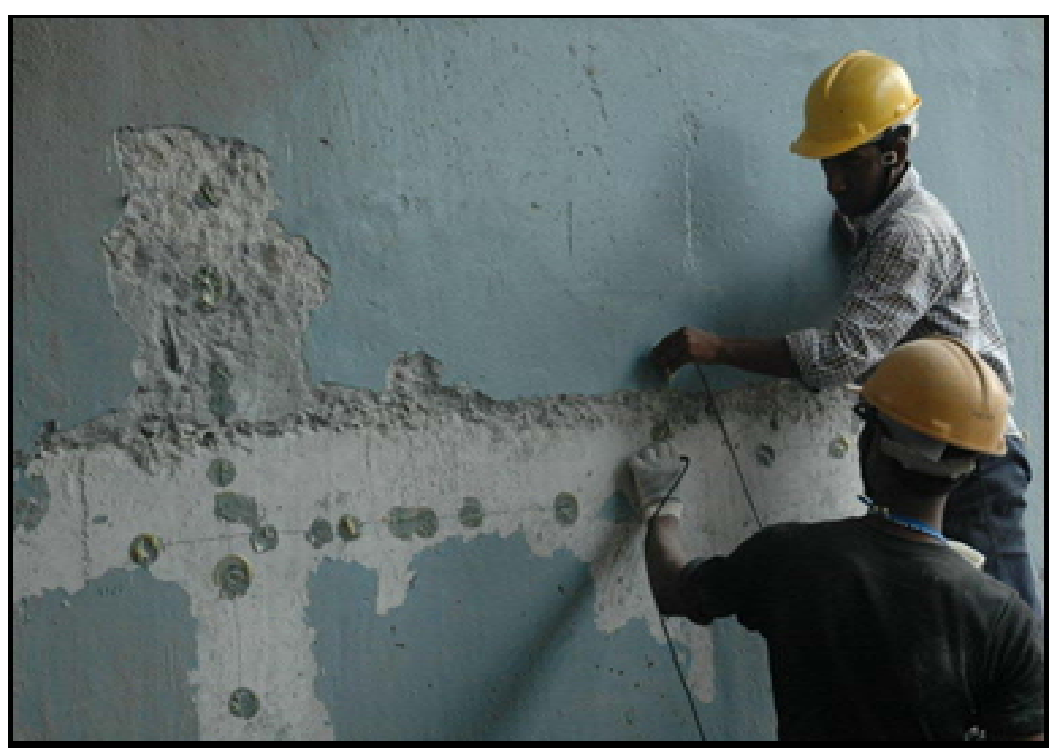

Fig.8: UPV testing is in progress.

From visual inspection and NDT it is clearly understood that all cracks are generated due to sudden generation of huge horizontal force at the bearing level and these cracks are very prominent in nature. Most of the cracks are through and through. Cause of distress is due to accidental load and further chance of generation of that kind of load is very minimum. Condition of concrete at other parts of foundation is in good condition, so it may be concluded that major distress of the structure is cracks these cracks are to be repaired properly. The following points may also be noted:

It was documented that original position of centreline of driving motor had slightly shifted outwards (about $10 \mathrm{~mm}$ ) horizontally.

All cracks were wide upto $10 \mathrm{~mm}$ in some cases.

- Two major cracks were generated along construction joints horizontally.

- One major crack was inclined in nature.

- Another major crack was vertical in nature.

\section{REPAIR METHODOLOGY}

During fixation / finalization of repair methodologies, following points were considered.

- All cracks are "dead" in nature and further chance for occurrence is very less. Cracks are to be filled with material which has high compressive strength, high bond strength and very low viscous properties.

- All cracks are to be sealed with proper compatible material to re-establish the structural integrity.

To re-establish the monolithic action of the concrete foundation, epoxy is recommended for following reasons.

- Cracks are to be sealed, so all positions of voids in crack are to be filled with epoxy - as it is a very low viscous material (CPS - 500) and material with a pressure of 3 to $4 \mathrm{~kg} / \mathrm{cm}^{2}$, it will reach every corner of voids.

- Epoxy concrete will have a better bond with concrete (Bond strength is around 30 to $40 \mathrm{~kg} / \mathrm{cm}^{2}$ ) to ensure proper monolithic action of concrete foundation.

- Low volume shrinkage of epoxy material will ensure further chance of creating gap inside the foundation cracks.

- Epoxy have very high vibrator damping capability and around 26 times higher than concrete.

- Epoxy posse's high tensile and compressive strengths in compares with concrete for proper structural behaviour and capable of arresting any further structural movement.

- Further structural movement of RC foundation is not at all acceptable. In order to ensure this, stitching with steel member was done along the crack line. Details of crack stitching is shown in Fig. No.9 


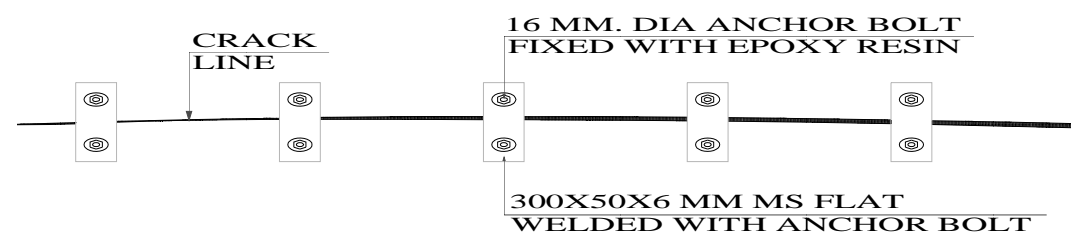

Fig.9: Details of steel stitching.

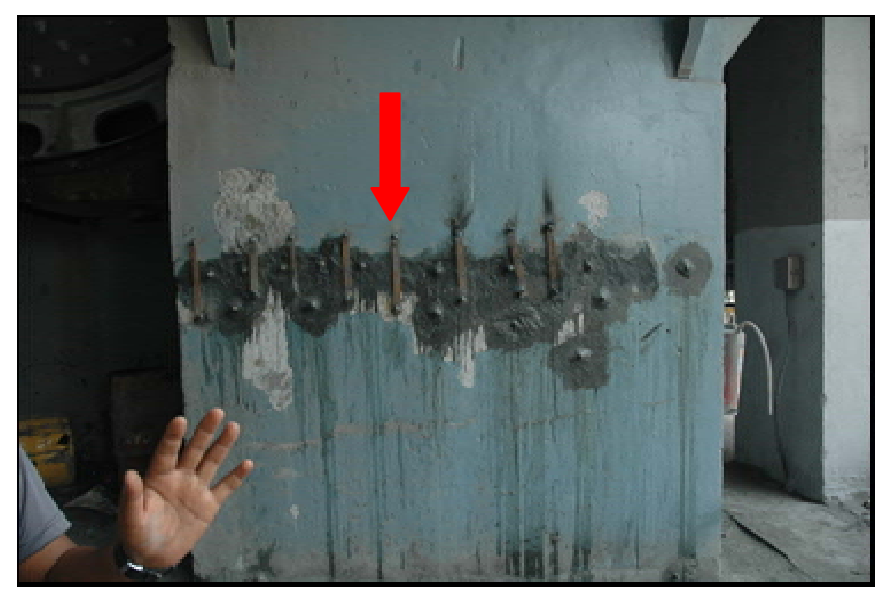

Fig.10: Photograph showing stitching with steel strip.

\section{CONCLUSION}

- Accidental load was the major cause of distress of RCC foundation of cement mill.

- Major cracks were generated along the construction joints of RCC foundation.

- Due to high compressive strength, bond strength and high penetrability epoxy pressure grout wasapplied for crack repairing, which seemed to be a very good solution for repairing for crack repair.

- The cement mill is in running condition for last one year and no further distress is noticed on the structure.

\section{REFERENCES}

[1] Donald M Harrison,“A Grouting handbook : A step by step guide to heavy equipment grouting”-Gult - Publishing.

[2] Jirsa, J.O., "Behavior of Epoxy-Grouted Dowels and bolts used for Repair or strengthening of R.C. Structures”, Proceedings, 9WCEE.

[3] ACI Committee 318, "Building Code Requirements for reinforced Concrete,” ACI 318-83, American Concrete Institute, 1983.

[4] Luke, Philip C.C., Chon, Carlos, Jirsa, J.O., "Use of Epoxies for Grouting Reinforcing Bar Dowels in concrete”, PMFSEL Report 852, Ferguson Structural Engineering Laboratory, University of Texas at Austin, September 1985.

[5] H. J. Degenkolb Associates, “Connections to existing Concrete for Seismic Rehabilitation” to be published in 1988.

[6] Bass, Robert A, Corrasquillo, Ramon L, Jirsa, J.O., "Interface Shear Capacity of Concrete Surfaces used in strengthening structures”, PMFSEL Report 85-4, December 1985.

[7] Winer, David F, "Behavior of steel to concrete connections used to strengthen existing structures”, M.S. Thesis, University of Texas at Austin, August 1985. 